\title{
A Comparision of the Effect of Sugammadex on the Recovery Period and Postoperative Residual Block in Young Elderly and Middle-Aged Elderly Patients
}

\author{
Emine Yazar ${ }^{1}$, Canan Yılmaz², Hülya Bilgin ${ }^{3}$, Derya Karasu², Selcan Bayraktar³, Y1lmaz Apaydın², \\ Halil Erkan Sayan ${ }^{2}$ \\ 'Department of Anesthesiology and Reanimation, Şırnak State Hospital, Şırnak, Turkey \\ ${ }^{2}$ Department of Anesthesiology and Reanimation, Bursa Şevket Yılmaz Training and Research Hospital, Bursa, Turkey \\ ${ }^{3}$ Department of Anesthesiology and Reanimation, Uludağ University School of Medicine, Bursa, Turkey
}

Background: The importance of the characteristics of anesthesia and postoperative residual curarization (PORC) in the elderly population should be a growing concern in this century.

Aims: To investigate the effect of sugammadex on the duration of the recovery from neuromuscular blocking agents and postoperative residual curarization in the young elderly and middle-aged elderly patients who underwent elective laparoscopic cholecystectomy, followed by a train of four (TOF) watch monitorization.

Study Design: Prospective clinical trial study.

Methods: Sixty patients over the age of 65 with American Society of Anesthesiologists I-III were divided into two groups according to their age (65-74 years old and $\geq 75$ years old). Patients received sugammadex $(2.0 \mathrm{mg} /$ $\mathrm{kg} \mathrm{iv}$ ) at the reappearance of the second twitch of the TOF as an agent for reversal of neuromuscular blockage at the end of surgery. Patients were extubated at the time of TOF $\geq 0.9$. The patients' TOF responses were evaluated with regards to PORC in at the 5th min- ute and were followed up for one hour in the recovery room. Reintubation was applied for those patients who developed PORC and had peripheric oxygen saturation $<90 \%$ despite being given $6 \mathrm{~L}$ oxygen per min with a face mask.

Results: The onset time of neuromuscular blocking agent and time from $\mathrm{T}_{2}$ to achieve TOF ratio $90 \%$ (the duration of sugammadex effect) or over were found to be longer in the middle-aged elderly group than in the young elderly group. A statistically significant relationship was found between age and the duration of TOF ratio to reach 0.9 in the same direction. The PORC incidence and rate of reintubation were found to be $1.7 \%$ in all patients.

Conclusion: In our opinion, it is necessary to remember that the duration of sugammadex effect on the recovery period is prolonged for patients who are aged $\geq 75$ years compared to patients aged between 65-74 years. (ClinicalTrials.gov Identifier: ACTRN12615000758505) Keywords: Elderly, postoperative residual curarization, reintubation, sugammadex
Young elderly people, middle-aged elderly people, and old elderly people have been classified, respectively, between 65 74 years of age, between 75-84 years of age, and over age 84 by gerontologists (1). A number of studies have indicated that the prevalance of postoperative residual curarization (PORC) increases with age $(2,3)$.
The principle of train of four (TOF) Watch was to indicate a pattern of stimulation that did not require the comparison of evoked responses to a control response obtained before administration of a neuromuscular blocking agent (NMBA). As well as enabling the observer to compare $T_{1}$ (first twitch of the TOF) to $\mathrm{T}_{0}$ (control), it also enables comparison of $\mathrm{T}_{4}$ (fourth

\footnotetext{
This manuscript was presented as an oral presentation at the $47^{\text {th }}$ Congress of Turkish Anesthesiology \& Reanimation Congress (TARK), 20-24 November 2013, Antalya, Turkey.

Address for Correspondence: Dr. Derya Karasu, Department of Anesthesiology and Reanimation, Bursa Şevket Yılmaz Training and Research Hospital, Bursa, Turkey Phone: +90 5057281175 e-mail: drderyatopuz@gmail.com

Received: 7 May $2014 \quad$ Accepted: 20 October $2015 \cdot$ DOI: $10.5152 /$ balkanmedj.2016.16383

Available at www.balkanmedicaljournal.org

Cite this article as:

Yazar E, Yılmaz C, Bilgin H, Karasu D, Bayraktar S, Apaydın Y, et al. A comparision of the effect of sugammadex on the recovery period and postoperative residual block in young elderly and middle-aged elderly patients. Balkan Med J 2016;33:181-7
} 
twitch of the TOF) to $T_{1}$. This is accepted as the TOF ratio. Throughout onset of non-depolarizing block, $\mathrm{T}_{4}$ disappears at about $75 \%$ depression of $\mathrm{T}_{1}, \mathrm{~T}_{3}$ at $80-85 \%$ depression of $\mathrm{T}_{1}$, and $\mathrm{T}_{2}$ at $90 \%$ depression. During recovery from non-depolarizing block: $\mathrm{T}_{1}$ appears again, first followed by $\mathrm{T}_{2}, \mathrm{~T}_{3}$, and finally $\mathrm{T}_{4}$ (4). In order to rule out PORC, a TOF ratio of 0.9 or over is considered to be a gold standard $(5,6)$.

The aim of the present study was to investigate the effect of sugammadex on the duration of recovery from NMBA and PORC in the young elderly and middle-aged elderly groups, followed by TOF-Watch monitorization.

\section{MATERIALS AND METHODS}

This prospective clinical trial was approved by local Ethics Committee (Bursa Şevket Y1lmaz Training and Research Hospital Ethics Committee) and Australian New Zealand Clinical Trials (Registry Number: ACTRN12615000758505). Sixty patients over the age of 65 , in whom laparoscopic cholecystectomy was planned and who are in American Society of Anesthesiologists (ASA) I-III group were included in the study after their informed consent was obtained. The patients were divided into two groups according to their age: the first were aged between 65-74 (young elderly, Group 1) and the second were aged $\geq 75$ (middle-aged elderly, Group 2). Patients with renal and hepatic failure, musculoskeletal disease, family history of malignant hyperthermia, and body mass index over 30 were excluded from the study. It was also planned to exclude patients who undergo laparatomy after failed laparoscopic intervention, whose operation period is over two hours, and who are admitted after operation to intensive care unit in intubated manner (Figure 1). Patients who are not administered premedication were taken to operating room and heart rate (HR), peripheral oxygen saturation $\left(\mathrm{SpO}_{2}\right)$, mean arterial pressure (MAP) and body temperature were monitored.

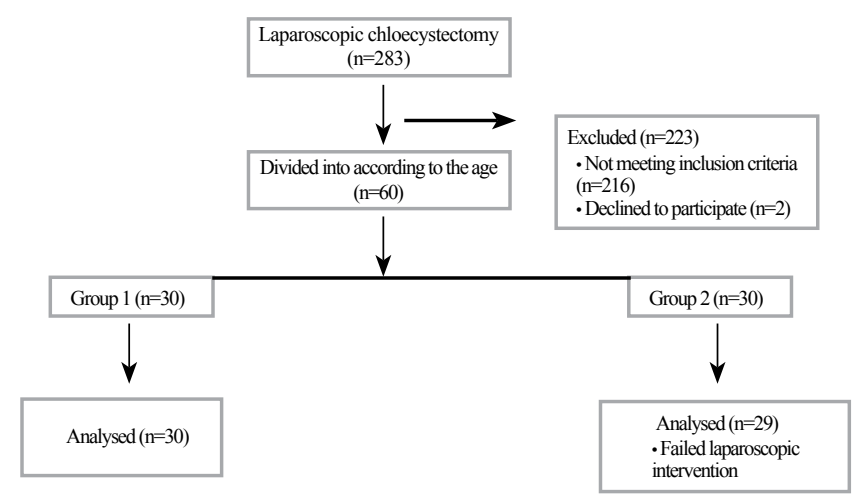

FIG. 1. Flow chart of patient enrolment and analysis
A train of four (TOF) Watch (TOF-Watch-SX Monitor, Organon Teknika; Oss, Netherlands) device was used to monitor nerve muscle transmission. Two surface electrodes were placed on the forearm ulnar nerve trace $2-3 \mathrm{~cm}$ apart, active and passive electrodes of the acceleromyograph and transducer was placed on the pulpa of the thumb. For sedoanalgesia, 0.03 $\mathrm{mg} / \mathrm{kg}$ midazolam (Zolamid, Defarma; Ankara, Turkey) and 1 $\mu \mathrm{g} / \mathrm{kg}$ fentanyl (Talinat, Vem; İstanbul, Turkey) iv was administered before calibration of the TOF-Watch device. Patients were preoxygenised for three minutes with $100 \%$ oxygen. TOF-Watch device was calibrated by supramaximal stimulation at $0.1 \mathrm{~Hz}$ frequency before induction. Propofol (Propofol, Fresenius-kabi; İstanbul, Turkey) $1.5 \mathrm{mg} / \mathrm{kg}$, lidocaine (Jetmonal $2 \%$, Adeka; İstanbul, Turkey) $1 \mathrm{mg} / \mathrm{kg}$, fentanyl $1 \mu \mathrm{g} /$ $\mathrm{kg}$, and rocuronium (Esmeron, MSD; İstanbul, Turkey) 0.6 $\mathrm{mg} / \mathrm{kg}$ iv were administered for anesthesia induction. Seventy $\mathrm{mA}$ supramaximal 4 TOF impulses were evaluated with 10 second intervals at $2 \mathrm{~Hz}$ frequency. When the TOF value was $0\left(\mathrm{~T}_{0}\right)$, the patients were intubated. The duration of time from the administration of NMBA to the $\mathrm{T}_{0}$ value was considered as the onset time of NMBA effect (I-T $\mathrm{T}_{0}$ ). Patients were ventilated with $50 \% \mathrm{O}_{2}+50 \% \mathrm{~N}_{2} \mathrm{O}$ and sevoflurane ( $\mathrm{E}_{\mathrm{T}} \mathrm{SEVO} 1.5 \%$ ) with $7 \mathrm{~mL} / \mathrm{kg}$ tidal volume and $12 \mathrm{breath} / \mathrm{min}$ respiration rate. When the TOF response was " 2 " $\left(\mathrm{T}_{2}\right)$, if operation was continuing maintenance dose $0.15 \mathrm{mg} / \mathrm{kg}$ iv rocuronium was administered, and if operation was being terminated, then $2 \mathrm{mg} /$ $\mathrm{kg}$ iv sugammadex (Bridion ${ }^{\circledR}$, MSD, Istanbul, Turkey) was administered. The duration of the time until TOF responses reach from $\mathrm{T}_{2}$ to $\mathrm{TOF}_{0.9}\left(\mathrm{~T}_{2}-\mathrm{TOF}_{0.9}\right.$ ) was recorded as the duration of sugammadex effect on recovery period and patients were extubated. $\mathrm{HR}, \mathrm{SpO}_{2}, \mathrm{MAP}$ values, skin temperature were recorded at the onset time, before induction and intubation time. $\mathrm{E}_{\mathrm{T}} \mathrm{CO}_{2}$ and $\mathrm{E}_{\mathrm{T}} \mathrm{SEVO}$ measurements were recorded during the intraoperative period. Skin temperature was kept within the range of $36-36.9{ }^{\circ} \mathrm{C}$. The duration of anesthesia, surgical time, the duration of NMBA effect $\left(\mathrm{I}_{-}-\mathrm{TOF}_{0.9}\right)$, the time of last NMBA administration and total amount of NMBA was recorded. The patients' $\mathrm{HR}, \mathrm{SpO}_{2}$, and MAP $\left(1^{\text {st }}, 30^{\text {th }}\right.$, and $60^{\text {th }} \mathrm{min}$ ) were monitored for an hour in the recovery room. In terms of PORC, the TOF responses were evaluated at the $5^{\text {th }}$ min. If TOF was $<0.9$, then postoperative residual curarization (PORC) was considered to be present and if TOF was $\geq 0.9$, it was considered to be absent. Cases with TOF $<0.9$ or who have findings suggestive of PORC (dyspneia, $\mathrm{SpO}_{2}<90$, being unable to swallow secretions) underwent TOF monitorization for an hour. Patients whose $\mathrm{SpO}_{2}$ value could not be kept over $90 \%$ despite the administration of $6 \mathrm{~L} / \mathrm{min}$ oxygen were reintubated. Pain experienced by the patients in the early postoperative period was evaluated with Visual Analog Scale (VAS) (0: no pain to 10: unbearable pain). In patients with 
a VAS score over $3,1 \mathrm{mg} / \mathrm{kg}$ diclofenac sodium (Dikloron, Deva; İstanbul, Turkey) im was administered. Speech, swallowing, secretions, skin color, and the consciousness of the patient were observed. Complications and side effects such as nausea, vomiting, bronchospasm, apnea, hypoventilation, hyperventilation, allergy, reintubation, tachycardia, bradycardia, hypotension, analgesic, and antiemetic requirements were recorded. When the patients had nausea and vomiting, $4 \mathrm{mg}$ ondansetron (Zofer, Adeka; İstanbul, Turkey) iv was given. The clinical condition of the patients was evaluated by Modified Aldrete Score (MAS) at their arrival in the recovery room and at the $30^{\text {th }}$ and $60^{\text {th }} \mathrm{min}$. If the score was 9 or over, then the patients were considered safe and they were sent to the clinic.

\section{Statistical evaluation}

Statistical analysis of the study was carried out using Statistical Package 21.0 for Windows (SPSS Inc.; Armonk, NY, USA). Shapiro-Wilk test was used as normallity test. Continuous variables were compared using Mann-Whitney U test when the data were not normally distributed. Wilcoxon Signed rank test was used for dependent groups. Categorical variables were compared using Pearson's Chi-squared test and Fisher's exact test. Correlations between variables were tested using Spearman correlation coefficient. Results were given as median (min-max) values. The $\mathrm{p}$ value of $<0.05$ was considered statistically significant and the values were expressed as "median-minimum-maximum" or as a number. The power calculation for the present study was calculated according to the $\mathrm{T}_{0.9}$ and an alpha level set at 0.05 . The power was calculated as 0.64 according to recorded sample size.

\section{RESULTS}

Since laparoscopic surgery was terminated and laparotomy was initiated, one patient was excluded from the study and

TABLE 1. Distribution of demographic characteristics, duration of anesthesia, operation, and duration of NMBA effect between the groups [number, median (minimum-maximum)]

\begin{tabular}{lccc}
\hline Characteristics & Group 1 $(\mathrm{n}=30)$ & Group 2 $(\mathrm{n}=29)$ & $\mathrm{p}$ \\
\hline Sex $(\mathrm{M} / \mathrm{F})(\mathrm{n})$ & $6 / 24$ & $7 / 22$ & 0.945 \\
Age (year) & $67.9(65-74)$ & $78.1(75-88)$ & 0.818 \\
ASA (I/II/III) (n) & $5 / 20 / 5$ & $4 / 20 / 5$ & \\
BMI (kg/m²) & $26.80(21.5-30)$ & $26.4(21.5-30)$ & 0.421 \\
Duration of anesthesia (min) & $64(35-120)$ & $60(35-116)$ & 0.964 \\
Duration of operation (min) & $42.5(15-116)$ & $40(15-90)$ & 0.903 \\
I-TOF $_{0.9}$ (min) & $42(20-98)$ & $40(15-85)$ & 0.089 \\
\hline
\end{tabular}

M: male; F: female; ASA: American Society of Anesthesiologists; BMI: body mass index; NMBA: neuromuscular blocking agent; $\mathrm{I}_{-} \mathrm{TOF}_{0.9}$ : duration of NMBA effect
59 patients were submitted to statistical evaluation. The demographic characteristics of the patients, duration of anesthesia, operation and the duration of NMBA effect $\left(\mathrm{I}_{-} \mathrm{TOF}_{0.9}\right)$ are shown in Table 1. It can be seen that there is no difference between the two groups $(\mathrm{p}>0.05)$. In the comparison of $\mathrm{HR}$,

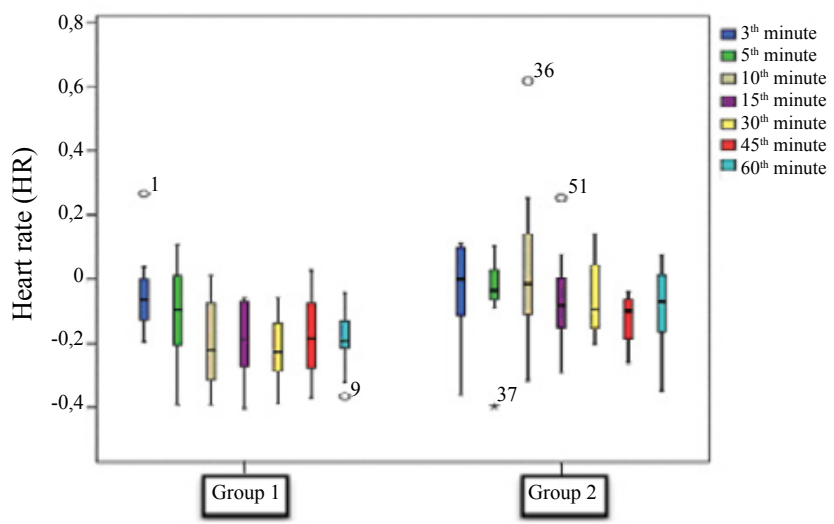

FIG. 2. A comparison of heart rate variability the between groups $\left(3^{\text {th }}, 5^{\text {th }}\right.$, $10^{\text {th }}, 15^{\text {th }}, 30^{\text {th }}, 45^{\text {th }}, 60^{\text {th }} \mathrm{min}$ )

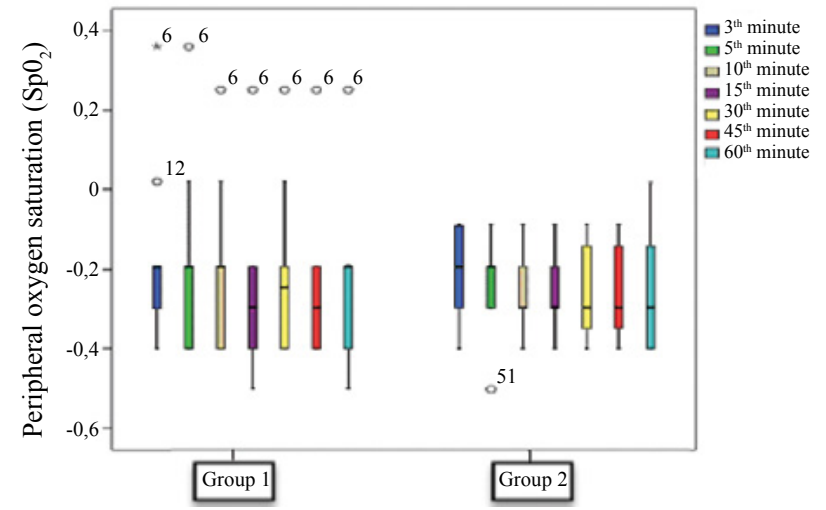

FIG. 3. Comparison of peripheral oxygen saturation between the groups $\left(3^{\text {th }}, 5^{\text {th }}, 10^{\text {th }}, 15^{\text {th }}, 30^{\text {th }}, 45^{\text {th }}, 60^{\text {th }} \mathrm{min}\right)$

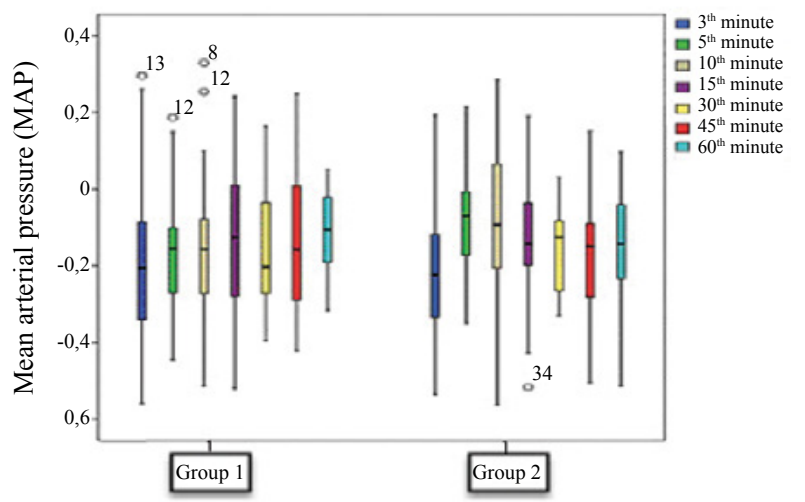

FIG. 4. Comparison of mean arterial pressure changes between the groups $\left(3^{\text {th }}, 5^{\text {th }}, 10^{\text {th }}, 15^{\text {th }}, 30^{\text {th }}, 45^{\text {th }}, 60^{\text {th }} \min \right)$ 
TABLE 2. Distribution of ETCO2 and ETSEVO values between the groups (mean \pm standard deviation)

\begin{tabular}{|c|c|c|c|}
\hline Characteristics & Group $1(n=30)$ & Group $2(n=29)$ & $\mathrm{p}$ \\
\hline Before intubation $\mathrm{E}_{\mathrm{T}} \mathrm{CO}_{2}$ & $23.03 \pm 7.36$ & $17.92 \pm 8.41$ & 0.64 \\
\hline After intubation $\mathrm{E}_{\mathrm{T}} \mathrm{CO}_{2}$ & $31.86 \pm 5.18$ & $31.46 \pm 6.16$ & 0.79 \\
\hline \multicolumn{4}{|l|}{$3^{\text {th }} \min$} \\
\hline $\mathrm{E}_{\mathrm{T}} \mathrm{CO}_{2}$ & $31.44 \pm 5.00$ & $33.14 \pm 4.65$ & 0.19 \\
\hline $\mathrm{E}_{\mathrm{T}} \mathrm{SEVO}$ & $1.28 \pm 0.42$ & $1.06 \pm 0.60$ & 0.12 \\
\hline \multicolumn{4}{|l|}{$5^{\text {th }} \min$} \\
\hline $\mathrm{E}_{\mathrm{T}} \mathrm{CO}_{2}$ & $32.17 \pm 4.07$ & $32.89 \pm 3.17$ & 0.45 \\
\hline $\mathrm{E}_{\mathrm{T}} \mathrm{SEVO}$ & $1.39 \pm 0.40$ & $1.13 \pm 0.55$ & 0.49 \\
\hline \multicolumn{4}{|l|}{$10^{\text {th }} \min$} \\
\hline $\mathrm{E}_{\mathrm{T}} \mathrm{CO}_{2}$ & $34.03 \pm 3.73$ & $34.03 \pm 3.31$ & 0.99 \\
\hline $\mathrm{E}_{\mathrm{T}} \mathrm{SEVO}$ & $1.43 \pm 0.40$ & $1.28 \pm 0.63$ & 0.29 \\
\hline \multicolumn{4}{|l|}{$15^{\text {th }} \min$} \\
\hline $\mathrm{E}_{\mathrm{T}} \mathrm{CO}_{2}$ & $34.68 \pm 3.07$ & $34.75 \pm 3.40$ & 0.94 \\
\hline $\mathrm{E}_{\mathrm{T}} \mathrm{SEVO}$ & $1.47 \pm 0.41$ & $1.33 \pm 0.60$ & 0.31 \\
\hline \multicolumn{4}{|l|}{$30^{\text {th }} \min$} \\
\hline $\mathrm{E}_{\mathrm{T}} \mathrm{CO}_{2}$ & $35.51 \pm 2.78$ & $35.26 \pm 3.99$ & 0.79 \\
\hline $\mathrm{E}_{\mathrm{T}} \mathrm{SEVO}$ & $1.16 \pm 0.68$ & $1.21 \pm 0.65$ & 0.78 \\
\hline \multicolumn{4}{|l|}{$45^{\text {th }} \min$} \\
\hline $\mathrm{E}_{\mathrm{T}} \mathrm{CO}_{2}$ & $37.30 \pm 6.57$ & $36.30 \pm 5.00$ & 0.56 \\
\hline $\mathrm{E}_{\mathrm{T}} \mathrm{SEVO}$ & $0.68 \pm 0.72$ & $0.75 \pm 0.76$ & 0.73 \\
\hline \multicolumn{4}{|l|}{$60^{\text {th }} \min$} \\
\hline $\mathrm{E}_{\mathrm{T}} \mathrm{CO}_{2}$ & $35.23 \pm 5.35$ & $34.81 \pm 4.44$ & 0.83 \\
\hline $\mathrm{E}_{\mathrm{T}} \mathrm{SEVO}$ & $0.21 \pm 0.54$ & $0.94 \pm 0.74$ & 0.38 \\
\hline \multicolumn{4}{|l|}{ Before extubation } \\
\hline $\mathrm{E}_{\mathrm{T}} \mathrm{CO}_{2}$ & $32.34 \pm 10.40$ & $31.75 \pm 11.56$ & 0.83 \\
\hline $\mathrm{E}_{\mathrm{T}} \mathrm{SEVO}$ & $0.07 \pm 0.04$ & $0.02 \pm 0.06$ & 0.35 \\
\hline
\end{tabular}

$\mathrm{SpO}_{2} \mathrm{MAP}, \mathrm{E}_{\mathrm{T}} \mathrm{CO}_{2}$ and $\mathrm{E}_{\mathrm{T}} \mathrm{SEVO}$ values no significant difference was found between the groups in the operating room ( $>0.05$ ) (Figure 2-4, Table 2).

Total amount of NMBA was not found to be different between Group 1 (44.1 mg) and Group 2 (45.8 mg) (p>0.05). The maintenance dose of rocuronium was administered to two patients in Group 1 and to six patients in Group 2. However, there was no significant difference between groups in terms of the number of patients administered maintenance dose of rocuronium ( $\mathrm{p}>0.05)$. The onset time of NMBA effect $\left(\mathrm{I}-\mathrm{T}_{0}\right)$ was found to be longer in Group 2 (2.4 min) than in Group 1 $(1.48 \mathrm{~min})(\mathrm{p}=0.009)$ (Table 3$)$. The time of the last NMBA administration was similar between the two groups ( $p>0.05$ ).

The duration of sugammadex effect on recovery period $\left(\mathrm{T}_{2}-\right.$ $\mathrm{TOF}_{0.9}$ ) was, respectively, $3.27 \mathrm{~min}$ and $5.5 \mathrm{~min}$ in patients in Group 1 and 2 (Table 3$)(\mathrm{p}<0.001)$. A moderately significant relationship was found between age and time to reach $\mathrm{TOF}_{0.9}$
TABLE 3. Onset time of NMBA effect and the duration of sugammadex effect on recovery period between the groups [number, median (minimum-maximum)]

\begin{tabular}{lccc}
\hline Characteristics & Group 1 $(\mathrm{n}=30)$ & Group 2 $(\mathrm{n}=29)$ & $\mathrm{p}$ \\
\hline $\mathrm{I}-\mathrm{T}_{0}(\mathrm{~min})$ & $1.48(1.07-6.16)$ & $2.4(1.36-6.58)$ & $0.009^{*}$ \\
$\mathrm{~T}_{2}-\mathrm{TOF}_{0.9}(\mathrm{~min})$ & $3.27(1.41-5.37)$ & $5.5(2.47-9.54)$ & $<0.001^{*}$ \\
\hline $\begin{array}{l}\mathrm{I}-\mathrm{T}_{0} \text { : onset time of NMBA effect; } \mathrm{T}_{2}-\mathrm{TOF}_{0.9}: \text { duration of sugammadex effect on } \\
\text { recovery period * } \mathrm{p}<0.05\end{array}$ & &
\end{tabular}

TABLE 4. Compare of VAS and MAS values according to $30^{\text {th }}$ and $60^{\text {th }}$ minutes between the groups [number, median (minimum-maximum)]

\begin{tabular}{lccc}
\hline Characteristics & Group 1 $(\mathrm{n}=30)$ & Group 2 $(\mathrm{n}=29)$ & $\mathrm{p}$ \\
\hline VAS 30 & $0.0(-7.0-0.0)$ & $0.0(-6.0-3.0)$ & 0.902 \\
VAS 60 & $0.0(-7.0-0.0)$ & $-1.0(-8.0-3.0)$ & 0.625 \\
MAS 30 & $0.0(0.0-2.0)$ & $0.0(-1.0-1.0)$ & 0.387 \\
MAS 60 & $0.0(0.0-2.0)$ & $0.0(-1.0-1.0)$ & 0.308 \\
\hline
\end{tabular}

VAS: Visual Analog Scale; MAS: Modified Aldrete Score

TABLE 5. Distribution of side effects and the need of analgesics/antiemetics between the groups (n)

\begin{tabular}{lccc}
\hline Characteristics & Group 1 $(\mathrm{n}=30)$ & Group 2 $(\mathrm{n}=29)$ & $\mathrm{p}$ \\
\hline Bradycardia & 2 & 2 & 1.000 \\
Arrhythmia & 1 & 1 & 1.000 \\
Bronchospasm & 2 & 0 & 0.492 \\
Nausea & 1 & 1 & 1.000 \\
Vomiting & 1 & 0 & 1.000 \\
Hypotension & 0 & 0 & - \\
Allergy & 0 & 0 & - \\
Analgesics & 8 & 12 & 0.358 \\
Antiemetics & 1 & 1 & 1.000 \\
\hline
\end{tabular}

$(\mathrm{r}=0.613)$. In Group 1, the duration of sugammadex effect on recovery period was 2.23 min earlier than in Group 2 .

Postoperative residual curarization was determined to have developed in one patient in Group 1 (3.3\%) and reintubation was performed. The rate of the development of PORC and reintubation was found to be $1.7 \%$ and $1.7 \%$ in all patients. There was no significant difference between the groups with respect to the rate of PORC development and reintubation ( $p>0.05$ ). In the comparison of HR, MAP changes and $\mathrm{SpO}_{2}$, no significant difference was found between the groups in the recovery room ( $p>0.05)$. No significant difference was found between groups in a comparison of VAS and MAS scores in recovery room (Table 4) $(\mathrm{p}>0.05)$. The number of patients with side effects is demonstrated in Table $5(\mathrm{p}>0.05)$.

\section{DISCUSSION}

In the present study, age-related effects of sugammadex as a reversal agent on recovery time and PORC in the recovery 
of neuromuscular block produced by rocuronium was investigated. It was established that the onset time of the NMBA effect $\left(\mathrm{I}-\mathrm{T}_{0}\right)$ and the duration of sugammadex effect on recovery period $\left(\mathrm{T}_{2}-\mathrm{TOF}_{0.9}\right)$ are more prolonged in patients who are $\geq 75$ than between 65-74 year olds. No significant difference was found between groups with respect to the rates of PORC.

There are many publications reporting that the onset time of intermediate term NMBA's effect is prolonged in elderly patients $(2,3,7)$. In the study of Matteo et al. (8), the time passing between the administration of rocuronium and the formation of neuromuscular block was found to be $4.1 \pm 1.5 \mathrm{~min}$ and $4.5 \pm 2.4 \mathrm{~min}$ in young (<60 age) and old ( $>70$ age) patients, respectively. In elderly patients, in relation to decrease in total body fluid, muscular, hepatic, and renal blood flow along with the fall in cardiac output, the onset time of NMBA effect is delayed (9).

However there are very few studies investigating the effect of age on the efficay of sugammadex. In the study of Suzuki et al. (10), while post tetanic count (PTC) was 1-2, the reversal effect of sugammadex $(4 \mathrm{mg} / \mathrm{kg})$ on neuromuscular blocking was investigated on 30 female patients monitored with acceleromyography, and it was found that the duration of the effect of sugammadex was prolonged three fold in older patients (aged $\geq 70$ ) compared to younger patients (aged 20-50). This was attributed to the delay in the duration of the effect of sugammadex owing to the decrease in cardiac output and muscular blood flow in the elderly. Decrease in blood flow was linked to reduction of vascular conduction associated with age and loss of muscular volume. Decreased blood flow leads to a slower increase of the plasma concentration of sugammadex and a decrease in the rate of free rocuronium molecules passing to plasma. Unlike this study, in our study sugammadex 2 $\mathrm{mg} / \mathrm{kg}$ was used and the 65-74 age group was compared with patients $\geq 75$ years of age. In the study of McDonagh et al. (11) $2 \mathrm{mg} / \mathrm{kg}$ sugammadex was applied to three groups, as follows: 18-64 years of age (adult), 65-74 years of age (elderly), and $\geq 75$ years of age (old elderly). The geometric mean time (95\% confidence interval) from sugammadex administration to recovery of the TOF ratio to 0.9 increased with age (adults $2.3 \mathrm{~min}$ and elderly, old elderly groups combined $2.9 \mathrm{~min}$ ). Recovery of the TOF ratio to 0.9 was estimated to be $0.7 \mathrm{~min}$ slower in elderly and old elderly groups compared with adults $(p=0.022)$. This was attributed to the slower distribution of sugammadex owing to the slower rate of dynamic circulation in elderly patients. It was stated that changes in the distribution and redistribution rates rocuronium, sugammadex and rocuronium-sugammadex complex may also play role in the alterations in muscular blood flow of elderly patients. In the present study, in the middle-aged elderly group, the duration of sugammadex effect on recovery period was prolonged by
2.23 min compared to the young elderly group. The study of McDonagh et al. (11) was phase 3a. Age related delay in the duration of sugammadex effect is related to many factors. In elderly patients, in addition to atherosclerotic changes, decrease in cardiac output, HR and muscular blood flow rate leads the onset of the effect of reversal agents, like other drugs, to be delayed (12). As a consequence of the decrease in regional blood flow, the duration of NMBA's and sugammadex effect is elongated $(10,11)$. A slower increase in the plasma concentration of sugammadex gives rise to slower diffusion of rocuronium from neuromuscular junction. As rocuroniumsugammadex complexes are excreted by kidneys, the effect of rocuronium and sugammadex is prolonged due to decreased clearance $(13,14)$.

The effect of inhalation anesthesia on peripheral tissue perfusion may contribute to age related changes in the effect of sugammadex (15). In our study, considering that different inhalation anesthetics may have different neuromuscular blocking effects, sevoflurane was used in all patients for standardization. Given that the duration of exposure to sevoflurane is similar in both groups, it is our belief that TOF measurements are not influenced by inhalation anesthesia.

The diagnosis of PORC is made based upon the monitorization of neuromuscular transmission and the evaluation of clinical symptoms and findings. Many studies have observed that monitorization of neuromuscular transmission decreases the frequency of PORC $(16,17)$. It is recommended that monitorization of neuromuscular transmission be performed primarily in elderly patients, in dysfunction of the kidney and liver, in patients with cardiovascular disease and asthma, in diseases involving neuromusculoskeletal system, in those who are morbidly obese, and in long lasting surgical interventions. In addition, in order to determine whether the respiratory events occurring in early stage of recovery emanates from NMBA or other anesthetic agents (opioid, benzodiazepin, volatile anesthetics), it is beneficial to monitor neurmuscular transmission. In the present study, neuromuscular transmission was monitored in the elderly population at high risk of PORC and a cut off value of TOF 0.9 was accepted in the determination of PORC. In the study of Hayes et al. (7), the incidence of PORC was higher in patients over the age of 65 than those under the age of 65 (respectively, $65 \%$, and $47 \%$ ). They attributed this to slower recovery of NMBA effects and a slower rate of reversal of neuromuscular transmission block in old patients compared to young patients. The incidence of PORC has been reported to vary between $53 \%$ to $93 \%$ in long acting NMBA's and between $3.5 \%$ and $95 \%$ in intermediate acting NMBA's $(18,19)$. In the study of Murphy et al. (20), in which rocuronium was used and neostigmine was administred as reversal agent, a TOF ratio of $<0.9$ was accepted for PORC definition and the 
incidence of PORC was found to be $30 \%$. In the present study, in which sugammadex was used as a reversal agent, the rate of PORC was found to be $1.7 \%$. In the observational study of Takagi et al. (21), it was found that after neostigmine and sugammadex were administered, the incidence of PORC was, respectively, $23.9 \%$ and $4.3 \%$. It was stated that sugammadex significantly decreased the rate of PORC and that PORC can be prevented at a rate of $80 \%$ with sugammadex.

Sugammadex makes a rapid, efficient, and reliable reversal state (22). As the recovery period is prolonged, the unsafe period after extubation is also prolonged (23). Duveldestin et al. (24) found that a sugammadex dose of $\geq 4 \mathrm{mg} / \mathrm{kg}$ enabled a more rapid recovery. In a case report by Eleveld et al. (25) of a 48 year old female patient who was undergoing general anesthesia, it was reported that $42 \mathrm{~min}$ after NMBA administration, while PTC was 1-2, following the administration of $0.5 \mathrm{mg} / \mathrm{kg}$ sugammadex, the patient had a TOF ratio of 0.9 and was completely awake, the TOF response temporarily regressed to the first twitch response. This was attributed to the inadequate dose of sugammadex, one patient was also diagnosed with PORC with superficialization of respiration in the recovery room, who suffered impairment in consciousness, a fall of $\mathrm{SpO}_{2}$ to $82 \%$ and $5^{\text {th }}$ min TOF ratio of 0.76 .

The limitation observed in this study is the absence of dosage investigation for faster recovery from neuromuscular transmission blockage in elderly patients. Further studies are required to determine the effective dosage of sugammadex in elderly patients, especially over the age of 74 . A further limitation was the small number of patients. Hence, further studies are required with a greater number of elderly patients.

In conclusion, it is necessary to remember that the duration of sugammadex effect on the recovery period is prolonged for patients who are aged $\geq 75$ years compared to patients aged between $65-74$ years.

Ethics Committee Approval: Ethics committee approval was received for this study from the ethics committee of Bursa Şevket Y1lmaz Training and Research Hospital.

Informed Consent: Written informed consent was obtained from patients who participated in this study.

Peer-review: Externally peer-reviewed. Externally peerreviewed

Author contributions: Concept - E.Y., C.Y., D.K.; Design - E.Y., C.Y., D.K., H.B.; Supervision - E.Y., C.Y., D.K., H.B.; Resource - E.Y., S.B., Y.A., H.E.S.; Materials - E.Y., C.Y., D.K.; Data Collection and/or Processing - E.Y.; Analysis and/or Interpretation - E.Y., C.Y., D.K., H.B.; Literature
Search - E.Y., S.B., Y.A., H.E.S.; Writing - E.Y., C.Y., D.K., H.B.; Critical Reviews - H.B.

Conflict of Interest: No conflict of interest was declared by the authors.

Financial Disclosure: The authors declared that this study has received no financial support

\section{REFERENCES}

1. Beğer T, Yavuzer H. Epidemiology of ageing and elderly. $J$ Geriatr 2012;25:13.

2. Xiaobo F, Jianjuan K, Yanlin W. Comparison of the variability of the onset and recovery from neuromuscular blockade with cisatracurium versus rocuronium in elderly patients under total intravenous anesthesia. Braz J Med Biol Res 2012;45:676-80. [CrossRef]

3. Arain SR, Kern S, Ficke DJ, Ebert TJ. Variability of duration of action of neuromuscular-blocking drugs in elderly patients. Acta Anaesthesiol Scand 2005;49:312-5. [CrossRef]

4. McGrath CD, Hunter JM. Monitoring of neuromuscular block. Contin Educ Anaesth Crit Care Pain 2006;6:7-12. [CrossRef]

5. Naguib M, Kopman AF, Ensor JE. Neuromuscular monitoring and postoperative residual curarisation: a meta-analysis. $\mathrm{Br} J$ Anaesth 2007;98:302-16. [CrossRef]

6. Onur O. Post-anesthesia recovery and problems. Basic Anaesthesia. Kecik Y (Ed). Gunes Medical Book Stores Co. Ltd. 2012.784-96.

7. Hayes AH, Mirakhur RK, Breslin DS, Reid JE, McCourt KC. Postoperative residual block after intermediate-acting neuromuscular blocking drugs. Anaesthesia 2001;56:312-8. [CrossRef]

8. Matteo RS, Ornstein E, Schwartz AE, Ostapkovich N, Stone JG. Pharmacokinetics and pharmacodynamics of rocuronium (Org 9426) in elderly surgical patients. Anesth Analg 1993;77:1193-7. [CrossRef]

9. Ozturk L, Izdes S. The safe use of anesthetics and neuromuscular and neuromuscular blockade reversal drugs in geriatric patients. Turkiye Klinikleri J Anest Reanim-Special Topics 2011;4:25-34.

10. Suzuki T, Kitajima O, Ueda K, Kondo Y, Kato J, Ogawa S. Reversibility of rocuronium-induced profound neuromuscular block with sugammadex in younger and older patients. $\mathrm{Br} \mathrm{An}$ aesth 2011;106:823-6. [CrossRef]

11. McDonagh DL, Benedict PE, Kovac AL, Drover DR, Brister NW, Morte JB, et al. Efficacy, safety and pharmacokinetics of sugammadex for the reversal of rocuronium-induced neuromuscular blockade in elderly patients. Anesthesiology 2011;114:318-29. [CrossRef]

12. Dinenno FA, Jones PP, Seals DR, Tanaka H. Limb blood flow and vascular conductance are reduced with age in healthy humans: relation to elevations in sympathetic nerve activity and declines in oxygen demand. Circulation 1999;100:164-70. [CrossRef] 
13. Sparr HJ, Vermeyen KM, Beaufort AM, Rietbergen H, Proost $\mathrm{JH}$, Saldien V, et al. Early reversal of profound rocuroniuminduced neuromuscular block by sugammadex in a randomized multicenter study: Efficacy, safety, and pharmacokinetics. Anesthesiology 2007;106:935-43. [CrossRef]

14. Gijsenbergh F, Ramael S, Houwing N, van Iersel T. First human exposure of Org 25969, a novel agent to reverse the action of rocuronium bromide. Anesthesiology 2005;103:695-703. [CrossRef]

15. Pühringer FK, Gordon M, Demeyer I, Sparr HJ, Ingimarsson J, Klarin B, et al. Sugammadex rapidly reverses moderate rocuronium- or vecuronium-induced neuromuscular block during sevoflurane anaesthesia: a dose-response relationship. $\mathrm{Br} J \mathrm{An}$ aesth 2010;105:610-9. [CrossRef]

16. Gatke MR, Viby-Mogensen J, Rosenstock C, Jensen FS, Skovgaard LT. Postoperative muscle paralysis after rocuronium: less residual block when acceleromyography is used. Acta Anaesthesiol Scand 2002;46:207-13. [CrossRef]

17. Debaene B, Plaud B, Dilly MP, Donati F. Residual paralysis in the PACU after a single intubating dose of nondepolarizing muscle relaxant with an intermediate duration of action. Anesthesiology 2003;98:1042-8. [CrossRef]

18. Murphy GS, Brull SJ. Residual neuromuscular block: lessons unlearned. Part I: definitions, incidence, and adverse physiologic effects of residual neuromuscular block. Anesth Analg 2010;111:120-8. [CrossRef]

19. Kaan MN. Postoperative residual neuromuscular blockade. Turkiye Klinikleri J Anest Reanim-Special Topics 2011;4:67-74.
20. Murphy GS, Szokol JW, Marymont JH, Greenberg SB, Avram MJ, Vender JS, et al. Intraoperative acceleromyographic monitoring reduces risk of residual neuromuscular blockade and adverse respiratory events in postanesthesia care unit. Anesthesiology 2008;109:389-98. [CrossRef]

21. Takagi S, Ozaki M, Kotake Y, Ochiai R, Suzuki T, Ogawa S, et al. Sugammadex has a lower incidence of postoperative residual curarization than neostigmine. American Society of Anesthesiologists Annual Meeting 2011.

22. Plaud B, Meretoja O, Hofmockel R, Raft J, Stoddart PA, van Kuijk JH, et al. Reversal of rocuronium-induced neuromuscular blockade with sugammadex in pediatric and adult surgical patients. Anesthesiology 2009;110:284-94. [CrossRef]

23. Illman HL, Laurila P, Antila H, Meretoja OA, Alahuhta S, Olkkola K. The duration of residual neuromuscular block after administration of neostigmine or sugammadex at two wisible twitches during Train-of-Four monitoring. Anesth Analg 2011;112:63-8. [CrossRef]

24. Duveldestin P, Kuizenga K, Saldien V, Claudius C, Servin F, Klein J, et al. A randomized, dose-response study of sugammadex given for the reversal of deep rocuronium- or vecuroniuminduced neuromuscular blockade under sevoflurane anesthesia. Anesth Analg 2010;110:74-82. [CrossRef]

25. Eleveld DJ, Kuizenga K, Proost JH, Wierda JM. A temporary decrease in twitch response during reversal of rocuroniuminduced muscle relaxation with a small dose of sugammadex. Anesth Analg 2007;104:582-4. [CrossRef] 